\section{Medical Education.}

I REGRET that I have not the time to do justice to Sir Archdall Reid's last letter, which is supposed to deal with the above subject (NATURE, January I3, p. 50). It is, as I expected, really an attempt to open up another discussion on evolution. Now since Sir Archdall confesses to having already spent eighteen months vainly trying to find out what biologists mean, it seems inadvisable to begin again; for his letter indicates a very imperfect acquaintance with biologists and their work.

To my mind it is an amazing suggestion that zoologists and botanists are incapable of teaching evolution, and it is illuminating indeed to find that men are to come after them "who have observed, with a minuteness and accuracy impossible to workers among plants and animals." I shall be glad to meet the gentlemen when they arrive. Meanwhile, until these Supermen appear, it is highly desirable that firstyear medicals, raw youths from school, should make their first acquaintance with the animal world through less expensive material than human bodies, and should approach a great profession with, what practice and theory have shown to be, the best introduction.

Department of Zoology, University, W. J. DAKIN. Liverpool, January I7.

\section{An Overlooked Feature in Four-legged Tadpoles of Rana temporaria.}

ALL accounts of the metamorphosis of the common frog leave it to be tacitly inferred that when the front legs make their way through the operculum branchial respiration ceases, and that thenceforth breathing is effected by the lungs, skin, and mucous membrane of the mouth. It appears to have been entirely overlooked that from the time of the acquisition of free front legs until the tail is completely

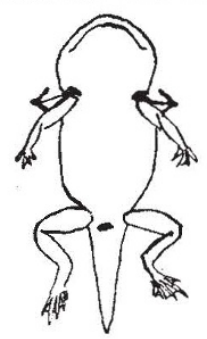

FIG. I.-Ventral view of four-legged tadpole of Kana tem. sorption of tail is nearly completed. nearly completed. The arrows mark water from the opercular chamber. absorbed, and the little anurous frog leaves the water, branchial respiration continues, water being drawn through the nostrils into the mouth, and discharged from the opercular chamber through a pair of crescentic apertures, one on each side immediately anterior to the base of the front leg.

In July I922 I was watching some tadpoles that had just acquired their front legs, and was keeping them in a shallow dish of pond water in which was a certain amount of suspended, finely divided solid matter. I observed that the tadpoles did not come to the surface of the water to breathe, but continued sitting at the bottom; and that the respiratory movements of the sides of the head were still proceeding in regular rhythm, but now were confined to the region posterior to the gape of the mouth, whereas prior to the appearance of the front legs the movements extended up to the extreme anterior end. Closer attention enabled me to detect minute solid particles occasionally entering the nostrils, and two fairly steady currents of water issuing from the posterior end of the head, one in front of the left and the other in front of the right leg.

On killing a few specimens I found a crescentic, slightly thickened lip bounding the anterior margin of each of these opercular openings, and was able to lift the flaps and pass bristles in at each, and out through the mouth, and conversely. This condition persisted until the absorption of the tail was completed.

Fearing that I might have encountered an abnormal family of tadpoles-they were rather unusually late in the season-I examined preserved specimens of which I have scores, collected years ago, in my laboratory for teaching purposes, and found exactly the same state of affairs in every one at this stage of development.

To make assurance doubly sure I had vertical longitudinal series of sections cut through four specimens ; and these fully confirm the naked-eye observations.

I have little doubt that others have noticed the thickened crescentic lips of the two opercular apertures; for in a figure published by Milnes Marshall, and in another by Howes "Atlas of Practical Elementary Zoology," I902 ed., Pl. ix. Fig. xiv.) it is indicated. Probably it has hitherto been mistaken for a line of fusion between the body wall and the remnant of the operculum left after the front legs have penetrated it.

Charterhouse, Godalming, January I2.

Oswald H. LatTer.

\section{Smell and Specific Gravity.}

IN the course of some other experiments which are being undertaken in the Psychology Department of the University of Edinburgh, a number of subjects were requested to arrange in serial order, according to smell, phials containing oil of cedar (C), origanum (O), sandalwood (S), and terebene (T). Twenty-two experiments were made in all, and tend to confirm the observations made by Haycraft, Cohn, Zwaardemaker, Heyninx, and others, with regard to odour and chemical constitution.

The serial arrangement was made, not according to the affect (pleasantness or unpleasantness) nor to the intensity, but according to "pitch," or " heaviness and lightness," "dulness and sharpness " of the sensation. The number of votes cast for the position of each substance in the series was as follows :-

$\begin{array}{rrrrr} & \text { I } & 2 & 3 & 4 \\ \mathrm{~S} & \text { I } 6 & 4 & \text { I } & \text { I } \\ \mathrm{C} & 4 & \text { II } & 4 & 3 \\ \mathrm{O} & 2 & 6 & \text { IO } & 4 \\ \mathrm{~T} & \ldots & \text { I } & 7 & \text { I } 4\end{array}$

A serial arrangement according to specific gravity is thus represented by the voting: sp. g. $\mathrm{S}=0.974^{-}$ $0.980, \mathrm{C}=0.939-0.96, \mathrm{O}=0.890-0.90$, and $\mathrm{T}=0.862-$ 0.868 . In nine out of twenty-two experiments the series was arranged without any error. The number of cases in which three of the osmyls were placed correctly was as follows: SCO Io, COT 9 , SCT I 4 , SOT I 5. SC and OT were correctly placed relatively to each other in $\mathrm{I}_{7}$ instances, $\mathrm{CO}$ in $\mathrm{I}_{4}, \mathrm{SO}$ and $\mathrm{CT} \mathrm{I} 9$, and ST (the two extremes) in $2 \mathrm{I}$ out of the 22 experiments.

The serial arrangement as recorded above is therefore by no means entirely due to chance, and the number of errors made diminishes the greater the difference between the specific gravities of the substances employed. As the above substances of the terpene group are not compounds but complex mixtures, moreover, as the subjects without any further explanation were only instructed to smell and arrange them in a series, the results are sufficiently striking. J. H. KENNETH.

\section{Edinburgh University,} January Io. 